\title{
Pedagogia freiriana e humanização: revisão de literatura da última década
}

\author{
Ketilin Mayra Pedro* \\ Clarissa Maria Marques Ogeda \\ Fernanda Delai Lucas Adurens ${ }^{* * *}$
}

\section{Resumo}

Paulo Freire ressignificou a maneira de olhar e ler o mundo, por meio da educação. A abordagem humanista foi um dos grandes legados da sua obra. Para o autor, a educação humanizadora envolve o olhar para pessoa como um sujeito, capaz de pensar, opinar, discordar, problematizar, e não como um objeto, passível de manipulação ou meramente de absorção de conhecimentos. Nesse contexto, o objetivo deste artigo consistiu em revisar sistematicamente a produção nacional stricto sensu relacionada à finalidade humanista da Educação proposta por Paulo Freire. Para tanto, realizou-se um levantamento na Biblioteca Digital Brasileira de Teses e Dissertações, utilizando-se os seguintes descritores: "paulo freire", "educação" e "humaniza\$". Ao se revisar sistematicamente a literatura, encontraram-se 68 dissertações e teses publicadas na última década, com picos de publicação nos anos de 2012 e 2015, sendo a grande maioria defendida nos Programas de Pós-Graduação em Educação de universidades públicas, quer estaduais, quer federais. Constatou-se que a grande maioria das pesquisas discorre sobre a formação docente com vistas à humanização dos sujeitos formados e também dos próprios formadores. Assim, verificou-se o quanto as contribuições basilares da Pedagogia Freiriana são multidisciplinares, atemporais e se aplicam às problemáticas atuais, que

* Doutora em Educação pela Universidade Estadual Paulista "Júlio de Mesquita Filho" com doutorado sanduíche na Universidade de Barcelona / Espanha. Docente e Diretora da Área de Ciência Humanas no Centro Universitário Sagrado Coração-UNISAGRADO. Bauru/SP. E-mail: ketilinp@yahoo.com.br

** Mestra em Educação pela Universidade Estadual Paulista "Júlio de Mesquita Filho”. E-Mail: clarissaogeda@gmail.com

*** Mestra em Educação pela Universidade Estadual Paulista "Júlio de Mesquita Filho”. E-mail: fernandadla10@gmail.com 
marcam a desigualdade social e desconsideram a diversidade cultural do nosso país.

Palavras-chave: Educação. Paulo Freire. Humanização.

\section{Freirean pedagogy and humanization: literature review of the last decade}

\section{Abstract}

Paulo Freire redefined the way of looking at and reading the world through education. The humanistic approach was one of the great legacies of his work. According to the author, humanising education means looking at the person as a subject, capable of being able to think, opine, disagree, problematise, and not as an object subject to manipulation, or merely knowledge absorption. In this context, the objective of this article was to systematically review the national sensu stricto production linked to the purpose of humanising education according to Paulo Freire. We conducted a survey at the Brazilian Digital Library of Theses and Dissertations using the following descriptors: "paulo freire", "education" and "humanize\$". When reviewing the literature systematically, we found 68 dissertations and theses published in the last decade, with its peak in 2012 and 2015, most of them being made by Postgraduate Education programs at public universities. It was found that the vast majority of research discusses teacher training with a view toward the humanisation of the students as well as the teacher themselves. Thus, we verify how much Freire's basic pedagogies are multidisciplinary, timeless and apply to the current issues of our society that reinforce inequality and disregard Brazil's cultural diversity.

Keywords: Education. Paulo Freire. Humanization

\section{Pedagogía freireana y humanización: revisión de literatura de la última década}

\section{Resumen}

Paulo Freire ha reinventado la manera de mirar y leer el mundo a través de la educación. El enfoque humanista fue uno de los grandes legados de su obra y para el autor, la educación humanizadora implica mirar a la persona como un sujeto, capaz de pensar, opinar, discrepar, problematizar y no como un objeto, susceptible de manipulación o simplemente de absorción de conocimientos. En ese contexto, el objetivo de este artículo consistió en revisar sistemáticamente la producción nacional stricto sensu relacionada 
con la finalidad humanista de la Educación propuesta por Paulo Freire. Para ello, realizamos un levantamiento en la Biblioteca Digital Brasileña de Tesis y Disertaciones utilizando los siguientes descriptores: "paulo freire", "educación” y "humaniza\$”. Al revisar sistemáticamente la literatura encontramos 68 disertaciones y tesis publicadas en la última década, con picos de publicación en los años 2012 y 2015, siendo la gran mayoría defendidas en los programas de Postgrado en Educación de universidades públicas, ya sean estatales o federales. Se constató que la gran mayoría de las investigaciones discurre sobre la formación docente con vistas a la humanización de los sujetos formados y también de los propios formadores. Así, comprobamos hasta qué punto las contribuciones básicas de la pedagogía freireana son multidisciplinares, atemporales y se aplican a las problemáticas actuales, que promueven la desigualdad social y desconsideran la diversidad cultural de nuestro país.

Palabras-clave: Educación. Paulo Freire. Humanización.

\section{Introdução}

O educador Paulo Freire nasceu no dia 19 de setembro de 1921, na cidade de Recife-PB, formou-se em Direito, curso vocacionado pela aproximação com o humanismo, mas optou pela educação e, diante da realidade brasileira nos anos 1950, com um contingente de população excluída do direito à educação, dedicou-se a uma nova proposta de alfabetização, conhecida como Pedagogia Freiriana ou Método Paulo Freire (FREIRE, 2018). Ficou largamente conhecido devido à iniciativa de reunir uma equipe de profissionais, em 1962, com o objetivo de alfabetizar adultos moradores da cidade de Angicos, localizada no sertão do Rio Grande do Norte.

No período da Ditadura Militar brasileira, Paulo Freire foi exilado e morou em diferentes países até regressar ao Brasil, em 1980; tornou-se professor na Pontifícia Universidade Católica de São Paulo e na Universidade Estadual de Campinas e, também, exerceu a função de Secretário da Educação no município de São Paulo, empossado por Luiza Erundina de Sousa, prefeita no período de 1989 a 1992 (FREIRE, 2018).

As inúmeras obras do autor são citadas nacional e internacionalmente, e este foi homenageado, em 2012, com o título de patrono da educação brasileira (FREIRE, 2018). 
Ana Maria Freire advertiu, em seu livro dedicado à vida e à obra de Freire, a maneira reducionista na qual algumas pessoas, inclusive educadores, consideram o Método, como uma mera sequência de técnicas. Frisou que não se pode separar do Método toda a teoria de conhecimento proposta por ele, carregada de aspectos políticos, éticos, democráticos e, acima de tudo, humanistas (FREIRE, 2018). O próprio Paulo Freire, em entrevista concedida ao semanário brasileiro O Pasquim, retomada por Cohn (2012, p. 61), aborda essa questão:

Eu tenho até as minhas dúvidas se se pode falar do método. E há, há um método. Aí é que está um dos equívocos dos que por ideologia, analisam o que fiz procurando um método pedagógico, quando o que deveriam fazer é analisar procurando um método de conhecimento, dizer: "mas, esse método de conhecimento é a própria pedagogia.” Entendes?

Considerando que o autor discorre sobre um modo crítico de ler, ser e agir no mundo, optamos por utilizar o termo Pedagogia Freiriana. Apesar de ser amplamente reconhecida pelo trabalho com a Educação de Jovens e Adultos (EJA), a proposta de Paulo Freire abrange todos os níveis da Educação Básica, desde a mais tenra idade até a adultez, no sentido de propiciar espaços democráticos, desenvolvimento da autonomia e valorização do diálogo, que requer a escuta do outro (FREIRE, 1996).

Os pressupostos teóricos da Pedagogia Freiriana permanecem atuais e provocativos no contexto contemporâneo. Seus princípios humanistas, éticos e políticos podem fundamentar estudos e pesquisas não apenas no campo da educação, como também em outras áreas do conhecimento.

A discussão sobre a finalidade humanista da educação foi um dos grandes legados da obra de Paulo Freire. Para ele, a educação humanizadora envolve o olhar para a pessoa como um sujeito, capaz de pensar, opinar, discordar, problematizar, atuando no mundo e com o mundo (FREIRE, 2008).

Diante do exposto, o objetivo deste artigo consistiu em revisar sistematicamente a produção nacional stricto sensu relacionada à 
finalidade humanista da Educação, proposta por Paulo Freire. Por meio da revisão sistemática, é possível potencializar a busca e levantar as produções, de maneira organizada e delineada (COSTA; ZOLTOWSKI, 2014).

\section{Método}

A fim de proceder a essa revisão, seguimos os pressupostos de Costa e Zoltowski (2014), pautados em Akobeng (2005), os quais consistem em: delimitar a questão a ser pesquisada; escolher as fontes de dados; eleger os descritores para a busca; levantar e armazenar os resultados; selecionar os artigos pelo resumo, de acordo com critérios de inclusão e exclusão; extrair os dados dos artigos selecionados e avaliá-los. Após essas etapas, concretiza-se a síntese e a interpretação (AKOBENG, 2005).

O levantamento foi realizado na Biblioteca Digital Brasileira de Teses e Dissertações (BDTD). Essa base de dados foi escolhida por reunir, em um único portal, todas as teses e dissertações defendidas em âmbito nacional, o que facilita e otimiza a busca.

Foram usados os descritores: "paulo freire", "educação" e "humaniza\$", interligados pelo operador booleano AND. O cifrão foi adotado como operador de truncamento, para abarcar todos os descritores que têm como raiz lexical o termo bumaniza.

Como critérios de inclusão dessa revisão, elencamos: ter sido publicado no intervalo temporal de 2010 a 2019; possuir, no assunto, título, resumo ou palavras-chave, os descritores citados e o objeto de análise ter sido a Pedagogia Freiriana, ou pesquisas com foco na humanização e respaldadas pelo referencial teórico de Paulo Freire.

\section{Resultados e discussões}

Foram levantadas 70 produções, sendo que 68 contemplavam os critérios de inclusão. As duas produções excluídas foram consideradas falso-positivas.

Do total, foram analisadas 48 dissertações e 20 teses. Esses dados refletem a maior quantidade de Programas de Pós-Graduação 
em nível de Mestrado, no Brasil. Segundo dados da Coordenação de Aperfeiçoamento Pessoal de Nível Superior (CAPES, 2019), existem no Brasil um total de 7.046 Cursos de Pós-Graduação, sendo 3.699 de Mestrado (profissional e acadêmico) e 2.442 de Doutorado, dados convergentes com os nossos achados de pesquisa.

No período selecionado para a análise, verificamos um constante aumento das pesquisas ligadas à Pedagogia Freiriana, com picos de publicação nos anos de 2012 (9) e 2015 (14). As produções encontradas estavam distribuídas em 27 instituições de Ensino Superior: federais, estaduais e particulares. A Universidade Federal de São Carlos contou com o maior número de publicações (12).

Ao examinarmos as áreas das pesquisas, identificamos 21 Programas de Pós-Graduação, de modo que a área da Educação concentra o maior número de publicações. No entanto, constatamos que áreas diversas das Ciências Exatas e da Saúde também empregam os pressupostos teóricos de Paulo Freire, para fundamentar e discutir seus achados de pesquisa, sendo esse autor utilizado como base em pesquisas advindas de 20 Programas de Pós-Graduação, além do Programa de Educação, que conta com 43 produções.

Por meio da análise dos objetos de pesquisa das dissertações e teses, estabelecemos 21 categorias temáticas. Estas estão expostas na Figura 01.

\section{Figura 01 - Categorias temáticas das produções analisadas}

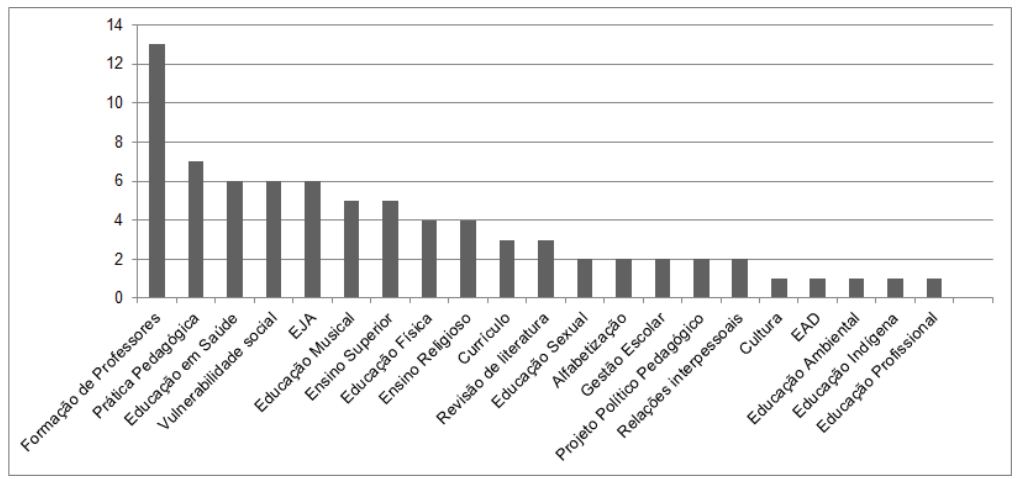

Fonte: Elaboração própria. 
A categoria que contou com maior número foi Formação de Professores, composta por 13 produções. As pesquisas que compõem essa categoria discutem a implementação de uma práxis humanizadora e a necessidade de formação permanente (PAULA, 2011; ZIMMER, 2011; ARAÚJO, 2012; SEVERINO, 2014; PINTO, 2019), formação de professores para o ensino de matemática, música, física, educação física, e uma pesquisa relacionada à disciplina de didática (SILVA, 2013; AMENT, 2015; MILHOMEM, 2016; VARGAS, 2018; MONTEIRO, 2019), o que nos revela, o quanto a pedagogia humanizadora é multi e transdisciplinar e pode oferecer respaldo teórico à diferentes campos de estudo. Também foram levantadas pesquisas voltadas à ludicidade (MENEZES, 2015), Ensino Fundamental, com foco na alfabetização visual (PEREIRA, 2015), bem como uma pesquisa direcionada às dificuldades de aprendizagem (BISPO, 2016). Para Nóvoa (2017), a formação docente está associada com a formação profissional; o autor alerta que só teremos a profissão docente forte e consolidada, quando essa deixar de ser desvalorizada e reduzida apenas às técnicas pedagógicas e domínio dos conteúdos curriculares.

Prática Pedagógica contou com sete publicações, com foco na humanização, autotransformação entrelaçada à educação popular, educação integral dos sujeitos, prática socioeducativa em contextos de vulnerabilidade, práticas interdisciplinares envolvendo especificamente a arte ou aliando-a a outras disciplinas, como língua portuguesa, história e física (ACCORCI, 2010; BRAGA, 2012; OLIVEIRA, 2014; SCHÜT'T, 2015; SIGNOR, 2016; FERREIRA, 2017; MASCIOLI, 2019).

As pesquisas mencionadas abordaram a relação dialógica da Pedagogia Freiriana e indicaram a importância de valorizar os conhecimentos dos educandos, a fim de, a partir desse ponto, impulsionar a construção de novos conhecimentos, vinculados aos seus interesses e realidades; ademais, evidenciaram a relevância de os professores avaliarem criticamente a própria prática, ressignificando-a e buscando novas possibilidades (FREIRE, 1996). 
A categoria Educação em Saúde foi representada por seis produções acadêmicas, e abarcou estudos sobre a saúde da mulher relacionados ao pré-natal, amamentação e incontinência urinária (JULIO, 2012; FAGUNDES, 2015; MENDES, 2017), bem como à práxis de profissionais da enfermagem (LOPES, 2012). Além disso, um estudo abordou a prevenção e o manejo de obstrução de vias aéreas em pequenas crianças (AMARAL, 2018) e outro, a percepção de professores quanto ao estudante que se encontra em educação hospitalar (RODRIGUES, 2016). Esses estudos demonstraram a interlocução entre as bases teóricas de Paulo Freire e a área da saúde, em que a humanização perpassa a relação entre as pessoas, considerando-os sujeitos únicos, ultrapassando assim um mero atendimento de saúde e avançando para um olhar holístico, integral e humano (FREIRE, 1996).

Quanto à categoria Vulnerabilidade social, foram levantadas seis dissertações e teses. Os temas enfocaram aspectos ligados à política de assistência social, alfabetização e práticas socioeducativas (ACCORCI, 2010; SOUZA, 2012; FARIA, 2016; LEMES, 2017; ALMEIDA, 2018; VILARRUBIA, 2019). Para Paulo Freire, a educação é uma prática de libertação, sendo que a liberdade não é considerada um fim, mas o meio para superar a alienação e, consequentemente, reduzir a desigualdade existente no campo social (COSTA, 2016).

Com relação à categoria $E J A$, tivemos seis estudos, entre os quais há os que analisam práticas pedagógicas e a formação permanente (FREITAS, 2015; LEITÃO, 2015; PINTO, 2019), além de evasão, vulnerabilidade social e saúde mental, nessa modalidade de ensino (BONFIM, 2012; SILVA; 2012; FARIA, 2016). A contribuição de Paulo Freire mais reconhecida nacional e internacionalmente relaciona-se com a EJA, a qual pode ser compreendida, basicamente, em duas etapas: $1^{a}$ levantamento do universo vocabular - conhecer o vocabulário de uso comum dos educandos e os temas presentes nas situações locais, que se ampliam para análise de problemas nacionais e regionais (FREIRE, 2008, 
p. 150); $2^{\mathrm{a}}$ escolha das palavras geradoras - seleção das palavras conhecidas dos educandos e posterior exploração do seu modo de escrita e significado, dialoga também sobre os temas da realidade daquele grupo, provocando a problematização e reflexão sobre a leitura de mundo que se amplia e se torna cada vez mais crítica com a leitura da palavra (FREIRE, 2008).

$\mathrm{Na}$ categoria Educação Musical, foram identificadas cinco produções que discutiram a respeito de análise e desenvolvimento de práticas musicais coletivas (AMENT, 2015; SILVA, 2015a; ARRUDA, 2016; JUSTINO, 2017) e de formação de educadores musicais (SEVERINO, 2014). Freire (1979) defendia que a educação não pode ser considerada apenas como uma ciência, mas também é arte, enquanto compreensão e reflexão da própria prática, ação e posterior conscientização.

A categoria Ensino Superior alocou cinco produções, as quais analisaram as contribuições dos projetos educativos para a docência, em um curso de administração (GODOI, 2015), a prática pedagógica e a didática, no ensino superior (COSCRATO, 2013; BICALHO, 2019; MONTEIRO, 2019) e, por fim, a espiritualidade a partir de vivências estudantis na extensão (BARRETO, 2013). A concepção freiriana de educação ancora também o Ensino Superior, de modo que os pressupostos sobre humanização e transformação social podem orientar o processo de ensino-aprendizagem em diferentes áreas do conhecimento (FREIRE, 1996).

A categoria Educação Física foi originada a partir de quatro produções, que abordaram socioeducação (MÜLLER, 2019), corporeidade (CASSIANO, 2014) e formação e percepção de professores, no âmbito da Educação Física (MILHOMEM, 2016; RODRIGUES, 2016). A dicotomia entre o corpo e mente, antes dos anos 1980, era dominante no currículo dessa disciplina, época em que Medina (1983 apud FRANÇOSO, NEIRA, 2014), com base nas reflexões de Paulo Freire, propunha uma redefinição da área, rompendo um paradigma estritamente estético e baseado em modismos, em direção a uma consciência crítica do papel do educador 
físico, na sociedade. A conscientização, seja do corpo, seja da mente, tem papel central nessa pedagogia.

Em Ensino religioso, reunimos quatro produções acadêmicas que discutiram pluralismo religioso (BALEEIRO, 2015), aproximação da pedagogia luterana e freiriana (SILVA, 2018), práticas na educação infantil (NOGUEIRA JUNIOR, 2018), educação, direitos humanos e evangelização (MENESES, 2017). Chaves et al. (2016) fazem aproximações entre a temática da espiritualidade e os pressupostos teóricos de Paulo Freire. Para os referidos autores, educação e espiritualidade são processos fundamentais na humanização dos indivíduos, de forma que a Pedagogia Freiriana apresenta aspectos libertadores em que a espiritualidade não contesta a educação enquanto ciência.

As produções da categoria Currículo (3) abordaram aspectos éticos (FURLAN, 2015), a análise epistemológica de um currículo municipal (BERTANHA, 2018) e a prática curricular freiriana em ciências (GOMES, 2014). Paulo Freire preconizava a construção do currículo em uma perspectiva crítica emancipatória, pautada no questionamento e na possibilidade de modificação da sociedade (MENEZES; SANTIAGO, 2014). A escolha do conteúdo programático é uma escolha política (FREIRE, 1996).

A categoria Revisão de Literatura contemplou três pesquisas, as quais versaram sobre o estágio curricular, no âmbito da formação de professores (SOUSA, 2018); a concepção do pensar certo na literatura freiriana (SILVA, 2015b), a história de vida e a interdisciplinaridade (CASADEI, 2014). Omote (2014) destaca a necessidade de analisar o corpus da pesquisa, nas mais variadas áreas, pois o avanço na produção do conhecimento acontece quando nos voltamos para o que já foi produzido, por meio de uma revisão da literatura.

Alocamos duas publicações na categoria temática Educação Sexual: uma delas abordou a aproximação teórica entre Freire e Marcuse (DEMARTINI, 2015), enquanto a outra, uma educação crítica libertadora, em escolas rurais colombianas e brasileiras (GARZON, 2019). Paulo Freire indicava a necessidade de os conteúdos estarem 
associados a uma leitura crítica da realidade, buscando assim a problematização e a conscientização dos problemas sociais, por meio do diálogo e da liberdade (MENEZES; SANTIAGO, 2014).

Em Alfabetização, contamos com duas pesquisas. A primeira focalizou o processo de aquisição da leitura e escrita mediada pelas tecnologias digitais (ARAÚJO, 2014) e a segunda, a alfabetização em contexto de vulnerabilidade social (VILARRUBIA, 2019). Precisamos ultrapassar a concepção de educação bancária, que considera os estudantes como indivíduos vazios a serem preenchidos, de sorte a pensar em práticas contextualizadas e que levem em conta os saberes prévios dos estudantes, porque somente assim teremos processos educativos, de fato, significativos (FREIRE, 1996).

A categoria Gestão escolar abarcou duas produções, que discutiram princípios e práticas para uma gestão escolar humanizadora (MIRA, 2017; KUHNEN, 2019). Com relação ao Projeto Político-Pedagógico (PPP), um estudo discutiu o documento enquanto espaço de reconstrução profissional docente (ROBAERT, 2015), ao passo que o outro, a emancipação pautada na voz dos estudantes (BARZ, 2010). O PPP é um documento político e democrático, o qual deve ser elaborado de modo colaborativo e preconizar o sentido humano e científico do planejamento. Assim, esse elemento pode ser considerado um instrumento de luta a favor da descentralização escolar e em busca de sua autonomia e qualidade (VASCONCELOS, 2000).

A temática das Relações Interpessoais foi contemplada em duas produções, uma abordando os princípios da convivência coletiva (GONÇALVES, 2012) e a outra, a experiência juvenil em atividades comunitárias (CORRÊA, 2013). Freire (1996) ressaltou a importância da afetividade, no processo educativo, desde que essa não interfira nas relações éticas entre professor e educando. Os professores precisam estar cientes da sua autoridade e compromisso ético, para assim propor práticas dialógicas que envolvam os educandos e estimulem o desenvolvimento da autonomia.

As categorias Cultura e Educação a Distância (EAD) tiveram uma produção cada; aquela versou sobre a cultura repressiva (SIL- 
VA, 2015c), enquanto esta construiu um modelo de referência para o ambiente on-line (FREIRE, 2010). Segundo Freire (2008), a cultura deve ser considerada como conteúdo programático da educação, sendo que qualquer indivíduo produz cultura, ao interagir na sua realidade. Sobre o uso da tecnologia, o autor não a demoniza, mas destaca a importância da sua utilização crítica e intencional (FREIRE, 1996).

As categorias Educação Ambiental, Educação Indígena e Educação Profissional foram representadas por uma produção cada, as quais abordaram respectivamente a complexidade na Educação Ambiental (FORTUNATO, 2010), a presença indígena no Ensino Superior (SILVA, 2017) e a constituição docente na Educação Profissional (PINTO, 2014). De acordo com Freire (1982, p. 95), há uma intrínseca relação entre educação e conhecimento: “[...] a educação, não importando o grau em que se dá, é sempre uma certa teoria do conhecimento que se põe em prática”.

\section{Considerações finais}

Ao revisar sistematicamente a produção nacional stricto sensu relacionada à finalidade humanista da educação proposta por Paulo Freire, encontramos 68 dissertações e teses publicadas na última década, com picos de publicação nos anos de 2012 e 2015, sendo a grande maioria defendida nos Programas de Pós-Graduação em Educação de universidades públicas, quer estaduais, quer federais.

A maior parte das pesquisas analisadas, tratou da formação docente, abordando a educação em diferentes áreas do conhecimento, com vistas à humanização dos sujeitos formados e dos próprios formadores. Relevante são também pesquisas que aproximam de Freire com outros autores, em diálogo profícuo para uma educação humanizadora. Olhares para crianças abrigadas, população de rua, população indígena, tratamento humanizado na saúde, assistência social, religião e espiritualidade, compõem um amplo campo de investigação demonstrando que o pensamento de Freire tem sido referência para uma multiplicidade de pesquisas que assumem o compromisso com a humanização da vida. 
Assim, verificamos o quanto as contribuições basilares da Pedagogia Freiriana são multidisciplinares, atemporais e se aplicam às problemáticas atuais, que marcam a desigualdade social e são ainda necessárias para dar visibilidade aos grupos minoritários e valorizar a diversidade cultural do nosso país.

Entre a utopia e a postura fatalista de um pessimismo abismal, optar pela realidade embasada em um pensamento humano e progressista parece o mais sensato. Sejamos nós, então, os precursores das pequenas mudanças, as quais, juntas, se tornam grandes e relevantes para o fortalecimento da democracia. Combatamos discursos de ódio, preconceitos e discriminações no nosso cotidiano, dentro ou fora das instituições de ensino. No Brasil, os ataques à Paulo Freire (1979) têm surgido de forma mais acirrada, exatamente pelo fato de propor a "práxis da libertação".

Não é de interesse das classes dominantes formar sujeitos críticos, com competências necessárias para ressignificar o espaço-tempo, como um ser social, histórico e cultural, com poder de atuar autonomamente sobre a própria vida. Tenhamos paciência histórica, porém, não sejamos nós os passivos.

\section{Referências}

ACCORSI, M. A vida em abrigos: um estudo sobre práticas sócio-educativas entre educadores e crianças abrigadas. 2010. Tese (Doutorado em Psicologia) Pontifícia Universidade Católica de São Paulo, São Paulo, 2010. Disponível em: https://tede2.pucsp.br/handle/handle/15955. Acesso em: 25 abr. 2020.

ALMEIDA, S. F. Andarilhos da esperança: estudo sobre a luta política impulsionada pela vida na rua e seus processos educativos sistematizada na experiência do Fórum da População de Rua de São Carlos/SP entre 2016 e 2017. 2018. Tese (Doutorado em Educação) - Universidade Federal de São Carlos, São Carlos, 2018. Disponível em: https://repositorio.ufscar.br/bitstream/handle/ufscar/9796/ALMEIDA_Sara_2018.pdf?sequence=4\&isAllowed=y. Acesso em: 25 abr. 2020.

AMARAL, J. B. Prevenção e manejo de obstrução de vias aéreas em crianças menores de um ano: um estudo de intervenção por simulação. 2018. Tese (Doutorado em Atenção à Saúde) - Universidade Federal do Triângulo Mineiro, Uberaba, 2018. Disponível em: http://bdtd.uftm.edu.br/handle/tede/641. Acesso em: 25 abr. 2020. 
AMENT, M. B. O PIBID na formação de educadores musicais: reflexões sobre os processos educativos na construção da identidade profissional. 2015. Dissertação (Mestrado em Educação). Universidade Federal de São Carlos, 2015. Disponível: https://repositorio.ufscar.br/handle/ufscar/2760?show=full. Acesso em: 25 abr. 2020.

ARAÚJO, M. L. F. O que fazer da educação ambiental crítico-humanizadora na formação inicial de professores de biologia na universidade. 2012. Tese (Doutorado em Educação). Universidade Federal de Pernambuco, Recife, 2012. Disponível em: https://repositorio.ufpe.br/bitstream/123456789/13022/1/ tese \%20Monica\%20final.pdf. Acesso em: 25 abr. 2020.

ARAÚJO, A. S. Alfabetização potencializada pela mediação digital na formação de alunos iniciantes do ensino fundamental: implicações político-pedagógica. 2014. Dissertação (Mestrado em Educação) - Universidade Federal de Sergipe, São Cristóvão, 2014. Disponível em: https://ri.ufs.br/bitstream/riufs/4881/1/AYALA_SOUSA_ARAUJO.pdf. Acesso em: 25 abr. 2020.

ARRUDA, M. F. V. Prática musical coletiva na Orquestra de Metais Lyra Tatuí: contribuições para o desenvolvimento humano. 2016. Dissertação (Mestrado em Educação) - Universidade Federal de São Carlos, São Carlos, 2016. Disponível em: https://repositorio.ufscar.br/handle/ufscar/7501?show=full. Acesso em: 25 abr. 2020 .

AKOBENG, A. K. Understanding systematic reviews and meta-analysis. Archives of Disease in Childhood, v. 90, p. 845-848, 2005. Disponível em: https:// www.ncbi.nlm.nih.gov/pubmed/16040886. Acesso em: 25 abr. 2020.

BALEEIRO, L.A. A escola como espaço de diálogo: o desafio do pluralismo religioso para o ensino religioso. 2015. Dissertação (Ciências da Religião) - Universidade Metodista de São Paulo, São Paulo, 2015. Disponível em: http://tede. metodista.br/jspui/handle/tede/1615. Acesso em: 25 abr. 2020.

BARRETO, B. M. V. B. Formação Universitária e Educação Popular: convergências com a Espiritualidade a partir de vivências estudantis na extensão. 2013. Tese (Doutorado em Educação) - Universidade Federal da Paraíba, João Pessoa, 2013. Disponível em: https://repositorio.ufpb.br/jspui/handle/tede/4717. Acesso em: 25 abr. 2020.

BARZ, C. A. Projeto Político Pedagógico em Ação: discutindo a emancipação de base freireana - a voz de educandos do Colégio Municipal Pelotense. 2010. Dissertação (Mestrado em Educação) - Universidade Federal de Pelotas, Pelotas, 2010. Disponível em: http://repositorio.ufpel.edu.br:8080/bitstream/prefix/2954/1/Lourdes $\% 20$ Helena $\% 20$ Rodrigues $\% 20$ dos $\% 20$ Santos_Tese.pdf. Acesso em: 25 abr. 2020. 
BERTANHA, A. A epistemologia em Freire e sua relação com o currículo da cidade de Sorocaba. 2018. Dissertação (Mestrado em Educação) - Universidade Federal de São Carlos (UFSCAR), São Carlos, 2018. Disponível em: https:/ / repositorio.ufscar.br/handle/ufscar/10433?show=full. Acesso em: 25 abr. 2020.

BICALHO, F. S. P. Descolonização do pensamento eurocêntrico na formação do estudante de direito: tensões entre o ensino e a tradição jurídica. 2019. Dissertação (Mestrado em Educação) - Universidade Federal de Ouro Preto, Mariana, 2019. Disponível em: http://bdtd.ibict.br/vufind/Record/UFOP_b0f405cdba749a9bad8bd980fb7f1671. Acesso em abr. 2020.

BISPO, S. A. S. Educação humanizadora e dificuldades de aprendizagem: o que nos revelam os discursos de professores dos anos iniciais do Ensino Fundamental? 2016. Tese (Doutorado em Letras) - Universidade Presbiteriana Mackenzie, São Paulo, 2016. Disponível em: http://tede.mackenzie.br/jspui/handle/ tede/3021. Acesso em abr. 2020.

BONFIM, S. V. M. S. A problemática da evasão de estudantes vinculados ao PROEJA no IF Baiano - Campus Guanambi. 2012. Dissertação (Mestrado em Educação Agrícola) - Universidade Federal Rural do Rio de Janeiro, Seropédica, 2012. Disponível em: https://tede.ufrrj.br/jspui/handle/jspui/1537. Acesso em: 25 abr. 2020.

BRAGA, M. M. S. C. Prática pedagógica docente-discente e humanização: contribuição de Paulo Freire para a escola pública. 2012. Tese (Doutorado em Educação) - Universidade Federal de Pernambuco, Recife, 2012. Disponível em: https://repositorio.ufpe.br/handle/123456789/13014. Acesso em: 25 abr. 2020.

CAPES. Dados do Sistema Nacional de Pós-Graduação. 2019. Disponível em: https://sucupira.capes.gov.br/sucupira/public/consultas/coleta/programa/ quantitativos / quantitativoAreaAvaliacao.jsf;jsessionid=IpC19tcuSCVdbQWNHKsjYjWE.sucupira-213. Acesso em: 22 abr. 2020.

CASADEI, S. R. O tempo e as histórias de vida: contribuições para a pesquisa interdisciplinar. 2014. Tese (Doutorado em Educação) - Pontifícia Universidade Católica de São Paulo, São Paulo, 2014. Disponível em: https://tede2.pucsp.br/ handle/handle/9818. Acesso em: 25 abr. 2020.

CASSIANO, N. N. O ser capoeirista e as possibilidades educativas: uma análise à luz da corporeidade. 2014. Dissertação (Mestrado em Educação Física) - Universidade Federal do Triângulo Mineiro, Uberaba, 2014. Disponível em: http:// bdtd.uftm.edu.br/handle/tede/198. Acesso em: 25 abr. 2020. 
CHAVES, A. C. et al. Educação e espiritualidade como experiências fundamentais para humanização em Paulo Freire. Revista Ciência em Movimento - Educação e Direitos Humanos. v. 18, n. 37, p. 37-46, 2016. Disponível em: https://www. metodista.br/revistas/revistas-ipa/index.php/EDH/article/viewFile/458/367. Acesso em: 25 abr. 2020.

COHN, S. Paulo Freire. Rio de Janeiro. Beco do Azougue, 2012.

CORRÊEA, J. S. Experiência de participação em atividades comunitárias: o olhar do jovem. 2013. Dissertação (Mestrado em Educação) - Pontifícia Universidade Católica de São Paulo, São Paulo, 2013. Disponível em: https://tede2.pucsp. br/handle/handle/3475. Acesso em: 25 abr. 2020.

COSCRATO, G. Concepções de graduandos de enfermagem sobre humanização e espiritualidade: uma pesquisa-ação. 2013. Tese (Doutorado em Enfermagem Psiquiátrica) - Universidade de São Paulo, Ribeirão Preto, 2013. Disponível em: https://teses.usp.br/teses/disponiveis/22/22131/tde-22012014-114941/ publico/GISELECOSCRATO.pdf. Acesso em: 25 abr. 2020.

COSTA, B. B. Paulo Freire: educador-pensador da libertação. Pro-Posições, Campinas, v. 27, n. 1, p. 93-110, abr. 2016. Disponível em: https://periodicos.sbu. unicamp.br/ojs/index.php/proposic/article/view/8645900. Acesso em: 25 abr. 2020 .

COSTA, A. B.; ZOLTOWSKI, A. P. Como escrever um artigo de revisão sistemática. In: KOLLER, S. H.; COUTO, M. C. P.; HOHENDORF, J. Manual de Produção Científica. Porto Alegre: Penso, 2014. p. 55-70. Disponível em: https:// www.biosanas.com.br/uploads/outros/artigos_cientificos/18/6505082c2a7c23986651c7b1f7a4a92e.pdf. Acesso em: 25 abr. 2020.

DEMARTINI, G. R. Articulação entre Paulo Freire e Herbert Marcuse para uma educação sexual humanizadora. 2015. Dissertação (Mestrado em Educação) - Universidade Federal de São Carlos, São Carlos, 2015. Disponível em: https:// repositorio.ufscar.br/handle/ufscar/2807?show=full. Acesso em: 25 abr. 2020.

FAGUNDES, D. Q. Ações construtivas de educação em saúde para o pré-natal. 2015. Dissertação (Mestrado em Saúde Coletiva). Universidade Federal do Espírito Santo, Vitória, 2015. Disponível em: http:/ /repositorio.ufes.br/handle/10/5564. Acesso em: 25 abr. 2020.

FARIA, M. L. C. A escrita é livre? contribuições da poesia lírica para além das grades. 2016. Dissertação (Mestrado Profissional em Letras) - Universidade Estadual do Oeste do Paraná, Cascavel, 2016. Disponível em: http:/ / tede.unioeste.br/ handle/tede/3459. Acesso em: 25 abr. 2020. 
FERREIRA, N. O. Leitura dialógica: a experiência da tertúlia literária em sala de aula. 2017. 161f. Dissertação (Mestrado em Gestão e Práticas Educacionais) - Universidade Nove de Julho, São Paulo, 2017. Disponível em: https://bibliotecatede. uninove.br/handle/tede/1604. Acesso em: 25 abr. 2020.

FORTUNATO, I. Meio-ambiente ou (meio-ambiente): a complexidade na educação ambiental. 2012. Dissertação (Mestrado em Educação) - Universidade Nove de Julho, São Paulo, 2012. Disponível em: https://periodicos.sbu.unicamp. br/ojs/index.php/etd/article/view/1304. Acesso em: 25 abr. 2020.

FRANÇOSO, S.; NEIRA, M. G. Contribuições do legado freireano para o currículo da Educação Física. Revista Brasileira Ciência Esporte, Florianópolis, v. 36, n. 2, p. 531-546, 2014. Disponível em: http://www.scielo.br/pdf/rbce/v36n2/ 0101-3289-rbce-36-02-00531.pdf. Acesso em: 25 abr. 2020.

FREIRE, P. Pedagogia da autonomia: saberes necessários à prática educativa. São Paulo. Paz e Terra, 1996.

FREIRE, P. Carta de Paulo Freire aos professores. Estudos Avançados, v. 15, n. 42, p. 259-268, 2001. Disponível em: http://www.scielo.br/scielo.php?script=sci_arttext\&pid=S0103-40142001000200013. Acesso em: 25 abr. 2020.

FREIRE, P. Conscientização: teoria e prática da libertação: uma introdução ao pensamento de Paulo Freire. Tradução Kátia de Mello e Silva. São Paulo: Cortez \& Morales, 1979.

FREIRE, P. Educação como prática da liberdade. 31. ed. Rio de Janeiro: Paz e Terra, 2008.

FREIRE, P. Educação: o sonho possível. In. BRANDÃO, C. R. (Org.) O educador: vida e morte. Rio de Janeiro: Graal, 1982. p. 89-101.

FREIRE, A. M. de A. Paulo Freire: uma história de vida. São Paulo. Paz e Terra, 2018.

FREIRE, E. P. A. Construindo um modelo de referência ao despertar do interesse dos sujeitos em projetos educativos em ambiente on-line. 2010. Dissertação (Mestrado em Educação) - Universidade Federal do Rio Grande do Norte, Natal, 2010. Disponível em: http://repositorio.ufrn.br:8080/jspui/handle/123456789/14416. Acesso em: 25 abr. 2020.

FREITAS, L. M. Interfaces entre o ensino médio regular e a juvenilização na EJA: diálogos, entrelaçamentos, desafios e possibilidades sobre quefazeres docentes. 2015. Dissertação (Mestrado em Educação) - Universidade Federal de 
Santa Maria, Santa Maria, 2015. Disponível em: https://repositorio.ufsm.br/handle/1/7219. Acesso em: 25 abr. 2020.

FURLAN, A. B. S. Concepção de um currículo crítico: a ética como referência praxiológica. 2015. Dissertação (Mestrado em Educação) - Universidade Federal de São Carlos, São Carlos, 2015. Disponível em: https://repositorio.ufscar.br/ handle/ufscar/6939?show=full. Acesso em: 25 abr. 2020.

GARZON, A. M. M. Educação crítica libertadora para a sexualidade do adolescente na escola rural, na Colômbia e no Brasil. 2019. Tese (Doutorado em Enfermagem) - Universidade Federal de Minas Gerais, Belo Horizonte, 2019. Disponível em: https://repositorio.ufmg.br/handle/1843/30999. Acesso em: 25 abr. 2020 .

GODOI, E. C. F. A docência em administração e algumas contribuições de projetos educativos. 2015. Dissertação (Mestrado em Educação) - Universidade Metodista de São Paulo, São Paulo, 2015. Disponível em: http://tede.metodista. br/jspui/handle/tede/1531. Acesso em: 25 abr. 2020.

GOMES, C. G. S. Da experiência não autêntica à busca por vivências humanizadoras: a prática curricular freireana em ciências. 2014. Dissertação (Mestrado em Educação) - Universidade Federal de São Carlos, São Carlos, 2014. Disponível em: https://repositorio.ufscar.br/handle/ufscar/8385. Acesso em: 25 abr. 2020.

GONÇALVES, L. D. O processo e o significado de elaborar princípios de convivência do trabalho coletivo à humanização: diálogos com Paulo Freire. 2012. Dissertação (Mestrado em Educação) - Universidade Federal de Pelotas, 2012. Disponível em: http://bdtd.ibict.br/vufind/Record/UFPL_c601cd51ae97af86e5705b103d7b7eb9. Acesso em: 25 abr. 2020.

JULIO, L. S. Desmame precoce: contribuição de uma prática educativa com trabalhadoras de enfermagem. 2012. Dissertação (Mestrado em Enfermagem) -Universidade Federal de Santa Catarina, Florianópolis, 2012. Disponível em: https:/ repositorio.ufsc.br/handle/123456789/84465. Acesso em: 25 abr. 2020.

JUSTINO, J. A. P. Educação musical humanizadora: uma experiência com crianças no campo da educação não formal. 2017. Dissertação (Mestrado em Educação) - Universidade Federal de São Carlos, São Carlos, 2017. Disponível em: https://repositorio.ufscar.br/handle/ufscar/9309. Acesso em: 25 abr. 2020.

KUHNEN, R. Da boca do monte ao bico da pena: por uma educação palotina humanizadora na Gestão de uma Escola Pública de Santa Maria/RS. 2019. Dissertação (Mestrado em Educação) - Universidade do Vale do Rio dos 
Sinos, Porto Alegre, 2019. Disponível em: http://www.repositorio.jesuita.org.br/ handle/UNISINOS/8772. Acesso em: 25 abr. 2020.

LEITÃo, E. S. S. A Prática Pedagógica Docente na Perspectiva da Humanização em Paulo Freire na EJA de Olinda. 2015. Dissertação (Mestrado em Educação) - Universidade Federal de Pernambuco, Recife, 2015. Disponível em: http://bdtd.ibict.br/vufind/Record/UFPE_ac43eb704e858d86a22fbdd5334cc4df. Acesso em: 25 abr. 2020.

LEMES, M. A. Estratégias de participação na política de assistência social na perspectiva de Paulo Freire. 2017. Tese (Doutorado em Educação) - Universidade do Vale do Rio dos Sinos, São Leopoldo, 2017. Disponível em: http:/ /www.repositorio.jesuita.org.br/handle/UNISINOS/6264. Acesso em: 25 abr. 2020.

LOPES, M. M. B. Educação em enfermagem na UFPA e a práxis da enfermeira na atenção básica de saúde. 2009. Tese (Doutorado em Enfermagem) - Universidade Federal de Santa Catarina, Florianópolis, 2009. Disponível em: https://repositorio.ufsc.br/handle/123456789/93047. Acesso em: 25 abr. 2020.

MASCIOLI, D. A. A. A formação em contexto na educação integral do ponto de vista dos professores de uma escola pública: uma análise da dialogicidade no processo educativo. 2019. Dissertação (Mestrado profissional em Educação) - Universidade Federal de São Carlos, São Carlos, 2019. Disponível em: https:// repositorio.ufscar.br/handle/ufscar/12314. Acesso em: 25 abr. 2020.

MENDES, A. Conhecer para prevenir e cuidar: pesquisa-ação para promover a saúde da mulher com incontinência urinária. 2017. Tese (Doutorado em Cuidado em Saúde) - Escola de Enfermagem, Universidade de São Paulo, São Paulo, 2017. Disponível em: https://teses.usp.br/teses/disponiveis/7/7141/tde-27042018103457/pt-br.php. Acesso em: 25 abr. 2020.

MENESES, J. P. D. O movimento de educação de base no período 1961-1964: qual a perspectiva de direitos humanos? 2017. Dissertação (Mestrado em Direitos Humanos) - Universidade Federal de Pernambuco, Recife, 2017. Disponível em: https://repositorio.ufpe.br/handle/123456789/25244?mode=full. Acesso em: 25 abr. 2020 .

MENEZES, M. G.; SANTIAGO, M. E. Contribuição do pensamento de Paulo Freire para o paradigma curricular crítico-emancipatório. Pro-Posições, Campinas, v. 25, n. 3, p. 45-62, dez. 2014. Disponível em: https://doi.org/10.1590/01037307201407503 . Acesso em: 25 abr. 2020. 
MENEZES, R. C. Práticas lúdico-reflexivas na formação de professores. 2015. Dissertação (Mestrado em Gestão e Práticas Educacionais). Universidade Nove de Julho, São Paulo, 2015. Disponível em: https://bibliotecatede.uninove. br/handle/tede/991. Acesso em: 25 abr. 2020.

MILHOMEM, S. R. Ciclos de escolarização: relação entre formação e prática docente dos professores de educação física. 2016. Dissertação (Mestrado em Educação) - Universidade Federal de Goiás, Jataí, 2016. Disponível em: https:// repositorio.bc.ufg.br/tede/handle/tede/6572. Acesso em: 25 abr. 2020.

MIRA, A. P. V. J. Princípios para a gestão escolar humanizadora a partir da perspectiva do humanismo em Paulo Freire. 2017. Dissertação (Mestrado em Educação) - Universidade La Salle, Canoas, 2017. Disponível em: http:/ / repositorio.unilasalle.edu.br/handle/11690/762. Acesso em: 25 abr. 2020.

MONTEIRO, A. R. Prática docente inspirada em Paulo Freire: um estudo desenvolvido na disciplina Didática em uma universidade comunitária. 2019. Tese (Doutorado em Educação: Currículo) - Programa de Estudos Pós-Graduados em Educação: Currículo, Pontifícia Universidade Católica de São Paulo, São Paulo, 2019. Disponível em: https://tede2.pucsp.br/handle/handle/22017. Acesso em: 25 abr. 2020.

MÜLLER, K. A. “O meu pouco, é muito aqui”! A educação física escolar na socioeducação. 2019. Dissertação (Mestrado em Ciências do Movimento Humano) - Universidade Federal do Rio Grande do Sul, Porto Alegre, 2019. Disponível em: https://lume.ufrgs.br/handle/10183/205198. Acesso em: 25 abr. 2020.

NOGUEIRA JUNIOR, S. P. Práticas de ensino religioso de docentes da educação infantil: tensões e possibilidades. 2018. Dissertação (Mestrado em Educação) - Universidade Católica de Santos, Santos, 2018. Disponível em: http:// biblioteca.unisantos.br:8181/handle/tede/4821. Acesso em: 25 abr. 2020.

NÓVOA, A. Firmar a posição como professor, afirmar a profissão docente. Cadernos de Pesquisa, v. 47, n. 166, p. 1106-1133, 2017. Disponível em: https:// doi.org/10.1590/198053144843. Acesso em 25 abr. 2020.

OLIVEIRA, M. C. P. Arte em Cena: teatro na escola pública como prática de liberdade. 2014. Tese (Doutorado em Educação, Arte e História) - Universidade Presbiteriana Mackenzie, São Paulo, 2014. Disponível em: http://bdtd.ibict.br/vufind/ Record/UPM_c37c60aa32c68bc7f54bbc31c41922cf. Acesso em: 25 abr. 2020.

OMOTE, S. Produção Acadêmica em Educação Especial. In: OMOTE, S.; OLIVEIRA, A. A. S.; CHACON, M. C.M. Ciência e Conhecimento em Educação Especial. São Carlos: Marquezine \& Manzini: ABPEE, 2014. p.13-24. 
PAULA, L. C. Contribuições da práxis histórica de Paulo Freire às pesquisas e propostas sobre educação contínua de educadores(as). 2011. Tese (Doutorado em Ciências Humanas) - Universidade Federal de São Carlos, São Carlos, 2011. Disponível em: https://repositorio.ufscar.br/handle/ufscar/2259?show=full. Acesso em: 25 abr. 2020.

PEREIRA, A. G. Alfabetização visual: uma perspectiva para auto(trans)formação permanente com professores. 2015. Dissertação (Mestrado em Educação) Universidade Federal de Santa Maria, Santa Maria, 2015. Disponível em: https:// repositorio.ufsm.br/handle/1/7220. Acesso em: 25 abr. 2020.

PINTO, F. C. Q. V. S. Formação permanente freireana: análise de políticas e práticas de formação de professores de EJA na DRE Pirituba-Jaraguá (SP). 2019. Tese (Doutorado em Educação) - Faculdade de Educação, Universidade de São Paulo, São Paulo, 2019. Disponível em: https://teses.usp.br/teses/disponiveis/48/48134/tde-25072019-131338/pt-br.php. Acesso em: 25 abr. 2020.

PINTO, L. M. C. S. A constituição do professor pelo trabalho docente na educação profissional: o caso do IFMT - Campus Cuiabá - Octayde Jorge da Silva. 2014. Tese (Doutorado em Educação) - Faculdade de Educação. Universidade Federal do Rio Grande do Sul, Porto Alegre, 2014. Disponível em: https:// lume.ufrgs.br/handle/10183/94744. Acesso em: 25 abr. 2020.

ROBAERT, S. Projeto político-pedagógicos: espaço de (re)construção profissional docente em uma perspectiva humanizadora. 2015. Dissertação (Mestrado em Educação) - Universidade Federal de Santa Maria, Santa Maria, 2015. Disponível em: https://repositorio.ufsm.br/handle/1/7218. Acesso em: 25 abr. 2020.

RODRIGUES, J. C. O corpo entre o riso e o choro na classe hospitalar. 2016. Dissertação (Mestrado em Educação Física) - Universidade Federal do Triângulo Mineiro, Uberaba, 2016. Disponível em: http://bdtd.uftm.edu.br/handle/ tede/350. Acesso em: 25 abr. 2020.

SEVERINO, N. B. Formação de educadores musicais: em busca de uma formação humanizadora. 2014. Dissertação (Mestrado em Educação) - Universidade Federal de São Carlos, São Carlos, 2014. Disponível em: https://repositorio.ufscar.br/handle/ufscar/2702?show=full. Acesso em: 25 abr. 2020.

SIGNOR, P. A auto(trans)formação permanente e a pedagogia de educação popular: entrelaçamentos possíveis entre a práxis educativa escolar e a realidade dos estudantes. 2016. Dissertação (Mestrado em Educação) - Universidade Federal de Santa Maria, Santa Maria, 2016. Disponível em: https://repositorio.ufsm.br/ handle/1/7265. Acesso em: 25 abr. 2020. 
SILVA, E. R. Cultura repressiva: o que pode a educação. 2015c. Dissertação (Mestrado em Educação) - Universidade Estadual de Londrina, Londrina, 2015c. Disponível em: http://bdtd.ibict.br/vufind/Record/UEL_b340156b837723d7bf7eaaafddcc1101. Acesso em: 25 abr. 2020.

SILVA, S. O pensar certo e a educação na obra de Paulo Freire. 2015b. Dissertação (Mestrado em Educação) - Universidade Estadual de Londrina, Londrina, 2015b. Disponível em: http://www.uel.br/pos/mestredu/images/stories/downloads/dissertacoes/2015/2015_-_SILVA_Sara.pdf. Acesso em: 25 abr. 2020.

SILVA, M. G. Criação musical coletiva com crianças: possíveis contribuições para processos de educação humanizadora. 2015a. Dissertação (Mestrado em Educação) - Universidade Federal de São Carlos, São Carlos, 2015a. Disponível em: https://repositorio.ufscar.br/handle/ufscar/2749. Acesso em: 25 abr. 2020.

SILVA, M. M. As contribuições da educação de jovens e adultos na construção de processos inclusivos no campo da saúde mental. 2012. Dissertação (Mestrado em Educação) - Universidade Federal de Minas Gerais, Belo Horizonte, 2012. Disponível em: https:// repositorio.ufmg.br/handle/1843/BUOS-8ZLL3X. Acesso em: 25 abr. 2020.

SILVA, N. B. Identidades, vozes e presenças indígenas na Universidade de Brasília sob a ótica da Análise de discurso crític $a$. 2017. Dissertação (Mestrado em Linguística) - Universidade de Brasília, Brasília, 2017. Disponível em: https:// repositorio.unb.br/handle/10482/31585? mode=full. Acesso em: 25 abr. 2020.

SILVA, R. S. Os indícios de um processo de formação: a organização do ensino no clube de matemática. 2013. Dissertação (Mestrado em Educação em Ciências e Matemática) - Universidade Federal de Goiás, Goiânia, 2013. Disponível em: https://repositorio.bc.ufg.br/tede/bitstream/tde/2964/5/Dissertacao\%20Rafael\%20Siqueira\%20Silva.pdf. Acesso em: 25 abr. 2020.

SILVA, W. F. Educação em Martinho Lutero e em Paulo Freire: tessitura de vida, conhecimento e emancipação na Pró Ludus (Gravatá - PE). 2018. Dissertação (Mestrado em Educação Contemporânea) - Universidade Federal de Pernambuco, Recife, 2018. Disponível em: https://repositorio.ufpe.br/bitstre$\mathrm{am} / 123456789 / 32570 / 1 /$ DISSERTA $\%$ c3\%87\%c3\%83O\%20William $\% 20$ Francisco $\% 20$ da $\% 20$ Silva.pdf. Acesso em: 25 abr. 2020.

SCHÜTT, K. R. O diálogo entre a física e a arte no renascimento: construindo uma proposta interdisciplinar envolvendo o estudo de pontes no ensino médio. 2015. Dissertação (Mestrado em Ensino de Física) - Ensino de Ciências (Física, Química e Biologia), Universidade de São Paulo, São Paulo, 2015. Disponível em: 
https://www.teses.usp.br/teses/disponiveis/81/81131/tde-14012016-153852/ publico/Kleber_Roberto_Schutt.pdf. Acesso em: 25 abr. 2020.

SOUSA, L. L. Estágio crítico-reflexivo na licenciatura: formação e desenvolvimento profissional docente? 2018. Tese (Doutorado em Educação) - Universidade de São Paulo, São Paulo, 2018. Disponível em: https://teses.usp.br/teses/disponiveis/48/48134/tde-14122018-095355/publico/LORENILSON_LEAL_DE_ SOUSA_rev.pdf. Acesso em: 25 abr. 2020.

SOUZA, R. V. P. A. O ensino formal da Fundação CASA e a interdisciplinaridade como busca de sentido para um novo currículo. 2012. Dissertação (Mestrado em Educação) - Pontifícia Universidade Católica de São Paulo, São Paulo, 2012. Disponível em: https://tede2.pucsp.br/bitstream/handle/9641/1/ Roberta\%20Vanessa\%20Pereira\%20Aranha\%20de\%20Souza.pdf. Acesso em: 25 abr. 2020 .

VARGAS, G. S. Uma abordagem do tema estruturante matéria e radiação no Curso Normal. 2018. Dissertação (Mestrado Profissional em Ensino de Física) Universidade Federal do Rio Grande do Sul, Porto Alegre, 2018. Disponível em: https://lume.ufrgs.br/bitstream/handle/10183/179759/001068187.pdf?sequence $=1$ \&isAllowed $=y$. Acesso em: 25 abr. 2020 .

VASCONCELOS, C. S. Planejamento: projeto de ensino-aprendizagem e projeto político pedagógico - elementos metodológicos para elaboração e realização. São Paulo: Libertad, 2000.

VILARRUBIA, E. F. Alfabetizar diante da vulnerabilidade social: um fazer possível e imprescindível. 2019. Dissertação (Mestrado em Programa de Estudos Pós-Graduados em Educação: Formação de Formadores) Pontifícia Universidade Católica de São Paulo, São Paulo, 2019. Disponível em: https://tede.pucsp.br/ bitstream/handle/22709/2/Eliana\%20Ferasin\%20Vilarrubia.pdf. Acesso em: 25 abr. 2020 .

ZIMMER, R. O. D. Entre medos e ousadias: resistências educativas pela reinvenção das lutas do "ser mais" e a atualidade do legado freireano. 2011. Tese (Doutorado em Educação) - Pontifícia Universidade Católica do Rio Grande do Sul, Porto Alegre, 2011. Disponível em: http://tede2.pucrs.br/tede2/handle/ tede/3664. Acesso em: 25 abr. 2020 